\title{
The Differences Between Constructing a Portfolio and Single Stock and How to Compare Their Performance
}

\author{
Hanpeng Dai ${ }^{1, *}$ \\ ${ }^{1}$ Lee Shau Kee School of Business and Administration, The Open university HongKong, HongKong SAR 999077, China \\ *Email:s1238302@ouhk.edu.hk
}

\begin{abstract}
This article aims at the China stock market. It will focus on the difference between the single stock and stock portfolio. This paper expounds and discusses the relevant problems of calculating portfolio income from the aspects of theory and practice. The research will choose two assets from both the Pro-cyclical and Counter-cyclical industries and use their return of stock to calculate the mean and standard deviation. It will also use efficient frontier to construct the Global Minimum variance portfolio. What's more, it also uses the Sharp ratio to further compare the differences between individual assets and portfolios. Through this research, the investor should know the importance of building a correct portfolio. The research shows that when the investor uses particular performance measures to compare the single stock and stock portfolio, the portfolio has greater performance than a single stock.
\end{abstract}

Keywords: Portfolio, Efficient Frontier, Sharpe ratio

\section{INTRODUCTION}

China's game industry has developed relatively late compared to other countries, since about the 1990s, arcade and console games have become popular in China. At that time, a legitimate game console like NES console would expense up to 1,500-2,000 RMB. However, in 1990, the average annual income of urban dwellers in China was only 1,387 RMB [1], which means only a few Chinese can enjoy the games, so it is impossible to develop China's game industry. Until the entry into the 21 st century, there was a huge increase of Chinese consumers who bought the computer. By 2005, the holding quantity of computers was 19.3 million, and it climbed to 66million in 2012. China also became the world's biggest computer market $[2,3]$. From that time, many game companies have emerged in China. At the same time, foreign game companies have released several games that have taken the world by storm, including League of Legends. Up to now, it is still the most popular computer game in the world, and millions of active gamers are online every year, and in China, there is an electric sports league. To sum up, the future of China's gaming industry will become better.

However, I found that there are still some risks in this industry. Teenagers' addiction to video games is a major problem. Many young people waste their time in school by indulging in games. This has become an irreconcilable conflict between the parents of the students and the game's company. Game companies want to earn more money, and parents want the government to control game companies and ban the sale of games. Considering that game industry is a huge industry, and it is impossible to destroy a large industry, so a series of policies have been introduced to regulate the game companies by the government, including limiting the length of time that minors can play games, which may reduce the popularity of a game [4]. Besides, I know that China's industry developed late, so there were a lot of imitation games in the market. Meanwhile, because of the high price of legitimate games, most people buy pirated games. This further squeezes the survival of domestic gaming companies. Many small companies went bankrupt as a result.

Game Industry as an Industry with both Opportunities and Risks. We can focus on this industry and make some proper investments, but we had better construct a portfolio to lower the risk and lock in profits. We know that the game industry is a Counter-cyclical industry, so the return and risk are instable, so I will choose an industry from the Pro-cyclical industry. I will select the real estate industry in the Pro-cyclical industry. The real estate industry has played a very important role in the national economy. Real estate's growth contributes about $20 \%$ to the nation's economic growth, 
and its added value is nearly $10 \%$ of GDP. Investment in real estate accounts for $25 \%$ of fixed-asset investment [5]. I will choose two assets from the game industry and real estate industry to construct the portfolio. I will use $\mathrm{R}$ studio to find different weights with particular assets, which results, including a chart, will be shown. Besides, I found an efficient frontier that all attainable portfolios with all risky assets. I will get numerous portfolios, finding a portfolio with the lowest risk in certainty return circumstance. Through this research, we can learn that although single stock may have an outstanding performance during a period of time, the return will be unsteady from long-term ownership levels. To reduce the volatility of risk, it is essential to construct a portfolio. What's more, constructing a portfolio and finding the optimal asset portfolio can help us maximize the benefits under stable risk circumstances. Above all, I want to help investors to understand the importance of constructing an asset portfolio. Investors should not only aim at the return of assets and randomly pick a single stock. They should also pay attention to basic information about the relative company. Finally, pick the stocks they want to invest in.

Next, I'll explain the structure of the article. In the next part, I will show the data of the two assets, including mean, standard deviation and so on. In part 3, I will give my empirical results. Part 4 will be my conclusion. I'll make a summary of my whole research, including what kinds of data I used to solve the question and the significance of this research. In Part 5, I will explain what can be done in the future to make the conclusion more convincing.

\section{DATA AND RESEARCH METHOD}

\subsection{Data}

I will choose two assets from the game industry and real estate industry. In the game industry, I will select Tencent, the largest game company in the world. This company make most of the Domestic games, including computer games and mobile games. Besides, Tencent also owns the most popular Instant messaging software, QQ, its QQ Instant Messenger having 711.7 million active users [1]. This also developed the game for Tencent to lay the foundation. In the real estate industry, I will choose Vanke. This is the largest residential development company in China.

The business covers 53 large, medium and small cities in China. It is also one of the earliest real estate companies in China. I search the stock data from 2017 to 2018. During this period of time, China and the United States were engaged in a trade war. China's stock market was volatile during the period, so I want to know if I construct a portfolio during that time, can I earn a stable return?
The detailed data was collected from GUOTAI JUNAN SECURITIES. This is the stock price Chart of two assets.

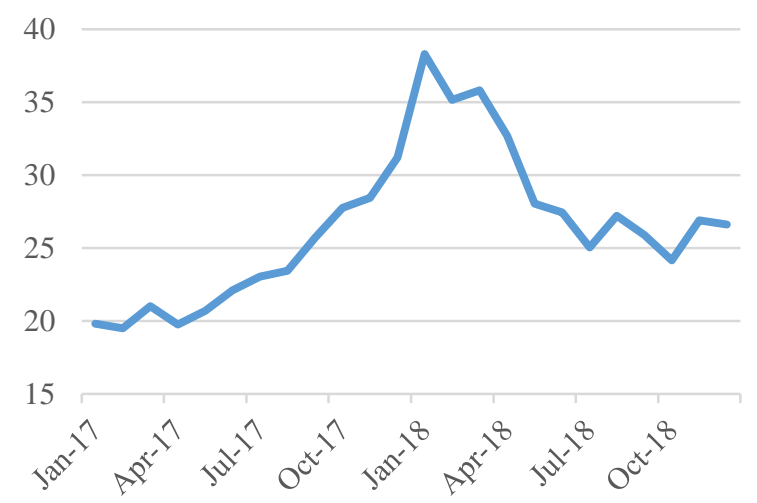

Figure 1. Stock price chart (Vanke)

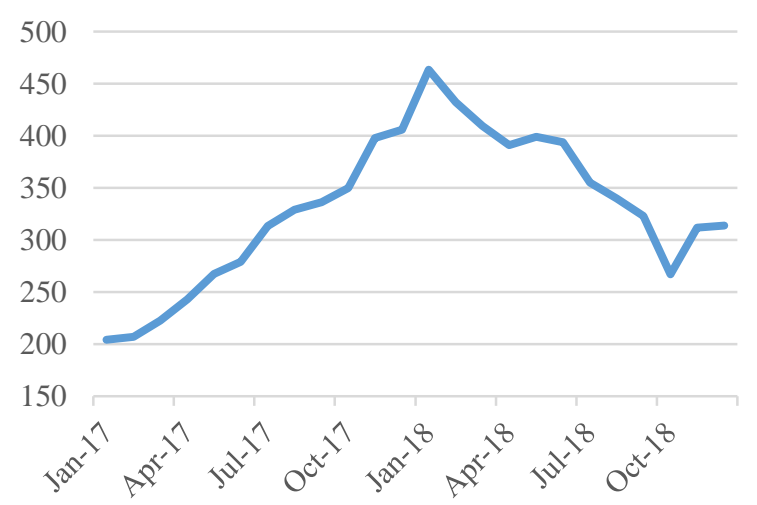

Figure 2. Stock price chart (Tencent)

Table 1. The annual return of Tencent and Vanke

\begin{tabular}{rll}
\hline Year & Tencent & \multicolumn{1}{c}{ Vanke } \\
\hline 2011 & 0.1800 & 0.0392 \\
2012 & 0.1699 & 0.0413 \\
2013 & 0.1451 & 0.0414 \\
2014 & 0.1396 & 0.0415 \\
2015 & 0.0949 & 0.0424 \\
2016 & 0.1047 & 0.0341 \\
2017 & 0.1307 & 0.0319 \\
2018 & 0.1105 & 0.0322 \\
2019 & 0.1005 & 0.0318 \\
2020 & 0.1201 & 0.0317
\end{tabular}

I found the information from the annual report of Tencent and Vanke from 2011 to 2020. Tencent is the largest game company globally, which keeps a high return of assets during the period. Only in 2015 the return of an asset is lower than $10 \%$. I think because of the rapid development of China's network construction, Tencent has rapid growth. What's more, Tencent released a national level mobile game, Honor of Kings, the most profitable game. It is one of the major reasons for Tencent to keep a high level of return on the asset. 
Back to Vanke, Real estate belongs to the real estate industry. It will have other kinds of costs, including facility costs and so on. I think it is one of the reasons that Vanke's return is lower than Tencent, although it is in a Pro-cyclical industry.

Table 2. Basic data with Tencent and Vanke

\begin{tabular}{lcc}
\hline & Tencent & Vanke \\
\hline Mean & 0.0246 & 0.0206 \\
Median & 0.0215 & 0.0219 \\
Standard deviation & 0.0833 & 0.0861 \\
Max & 0.1685 & 0.2276 \\
Min & 0.1739 & -0.1422
\end{tabular}

Based on stock returns, we can easily calculate the mean and standard deviation of two stocks between 2017 and 2018. However, in the stock market, the return of the two assets don't have an obvious difference, which is 0.0245 and 0.0206 , respectively. Besides, comparing the standard deviation of two assets, it also doesn't have a significant discrepancy, 0.0833 and 0.0861 , respectively. In addition, in mathematical, the mean will represent return, and standard deviation will represent risk. When the standard deviation is higher, income instability and risk are higher, so if the standard deviation is lower, the risk is lower. Between Tencent and Vanke, I found that if investors invest the same sum of money, Tencent may bring the investor more return than Vanke. Investors also have a higher probability of losing money.

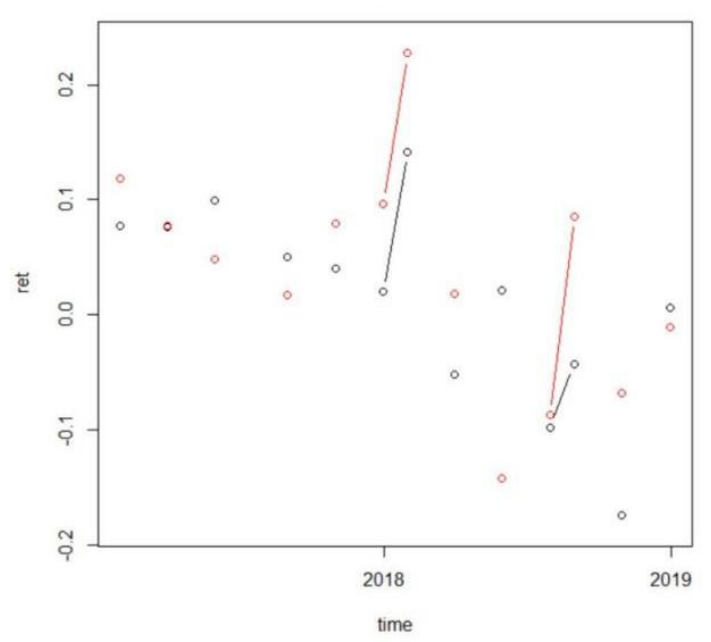

Figure 3. Time series plot comparison between Tencent and Vanke (ret means return, time is from 2017-2019,

the point in this chart represent return in particular time).

Chart 2 shows the comparison of the time series plot of two assets. The red point and line are represented Tencent, and the black one represents Vanke. In this chart, when I see the secular trend, it is clear that both
Tencent and Vanke have a declining trend of the rate of increase during these two years. It also forecasts that both two countries will also have a declining trend of the rate of increase in the next year. In addition, as we can see in the chart, in both of the two years, the rate of stock about Tencent show a Seasonal variation of down-up, which means when towards the end of the year, Tencent will have a good performance in the market. Compared to Tencent, Vanke is more stable, although it also had significant ups and downs. This justifies what I said in the last paragraph: Vanke has a lower standard deviation and lower volatility of the rate of return.

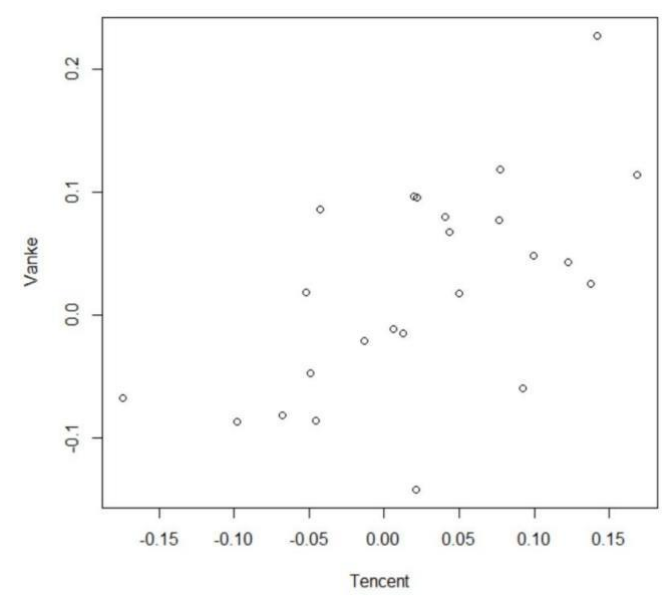

Figure 4. Scatterplot between two assets

Table 3. Correlation between two assets

\begin{tabular}{lcc}
\hline & Tencent & Vanke \\
\hline Tencent & 1.0000 & 0.5951 \\
Vanke & 0.5951 & 1.0000 \\
\hline
\end{tabular}

In chart 3, we can find that the chart's points have an increasing trend, and it looks like a straight line from the diagonal. This shows that there is a weak relationship exists between the two companies. In table 3, I know that the correlation between the two companies is 0.5951 , it is between 0.3 and 0.8 , and it can be considered a weak correlation. Therefore, we can conclude that the 2 variables are independent.

\subsection{Methodology}

\subsubsection{The Mean and Standard Deviation of Portfolio}

There are now two assets, Tencent and Vanke. We consider Tencent as asset 1 and Vanke as asset 2, so the stock return of Tencent is $\mathrm{R} 1$, and the return of Vanke is R2. Because only two assets are in the portfolio, I set the weight of assets 1 as W1 and 2 as W2, so the portfolio return is listed as follows. [6]

$E\left(r_{p}\right)=w_{1} E\left(r_{1}\right)+w_{2} E\left(r_{2}\right)$ 


$$
\begin{aligned}
& w_{1}+w_{2}=1 \\
& w_{2}=1-w \\
& \text { Then, } \\
& E\left(r_{p}\right)=w_{1} E\left(r_{1}\right)+\left(1-w_{1}\right) E\left(r_{2}\right)
\end{aligned}
$$

In the same way, we can calculate the portfolio's standard deviation.

$$
\sigma_{p}=\sqrt{w_{1}^{2} \sigma_{1}^{2}+w_{2}^{2} \sigma_{2}^{2}+2 w_{1} w_{2} \sigma_{1} \sigma_{2} \rho_{1,2}}
$$

In addition, $\rho_{1,2}$ is the correlation that had been shown in the data and the specific value is 0.5951 .

\subsubsection{Efficient Frontier}

A minimum variance set is the set of all portfolios that have the least volatility for each level of possible expected return. An efficient set (frontier) is the part of the minimum variance frontier that offers the highest expected return for each standard deviation level. The concept of efficient frontiers and optimal portfolio selection was originated by Harry Markowitz in 1952 [6]. The shape of the Efficient frontier will be demonstrated below.

We know the return and the correlation between single stock. The only unknown quantity is weights. I use the $\mathrm{r}$ studio to set 1000 portfolios, each portfolio have different weight of two assets. There is the chart of Efficient frontier.

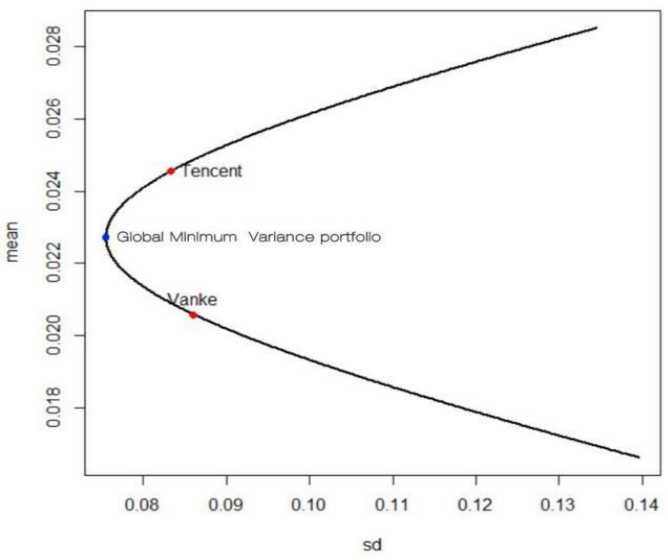

Figure 5. The efficient frontier of portfolio

There are two specific points in the chart. The higher point named Tencent means investor invest single stock, it is the same meaning of another red point. There are 1000 portfolios, and which one is I looking for? I've already marked it on the chart. That is the portfolio I am looking for. It is the Global Minimum Variance portfolio, which means at this point, under the lowest risk circumstance, you can earn the most amount of return. At the same time, I can also figure out the weight of two assets. There is the table shows the data below.
Table 4. The mean and standard deviation of the portfolio

\begin{tabular}{ll}
\hline & \multicolumn{1}{c}{ Portfolio } \\
\hline Mean & 0.0227 \\
Standard deviation & 0.07556 \\
\hline
\end{tabular}

Table 5. The weight of assets in the portfolio.

\begin{tabular}{lll}
\hline & Tencent & Vanke \\
\hline Weight & 0.5405 & 0.4596 \\
\hline
\end{tabular}

Compared with two single stocks, although the portfolio's return is lower than the single stock (Tencent), but the risk is significantly reduced.

I also use the Sharpe ratio to compare the portfolio with two single stocks. The objective is to calculate how much excess return will be generated for each unit of total risk in the portfolio [7].

$S P I=\frac{E\left(R_{p}\right)-R_{f}}{\sigma_{p}}$

$R_{f}$ means risk-free rate, which is the return of the risk-free asset, but in the research, there is no risk-free asset, so when calculating the Sharpe ratio, the $R_{f}$ is zero. Here is the table of three assets' Sharpe ratios.

Table 6. Sharpe ratio of three assets

\begin{tabular}{llll}
\hline & Tencent & Vanke & Portfolio \\
\hline Sharpe ratio & 0.2948 & 0.2392 & 0.3007 \\
\hline
\end{tabular}

\section{EMPIRICAL RESULTS}

\subsection{Content of Study}

In this part, I will integrate all the data from the previous portfolio and compare it to a single stock. The portfolio data corresponds to Table 2. According to table 4 , we know that the mean and standard deviation are 0.0227 and 0.0755 , respectively. Besides, we know that the Sharpe ratio is 0.3007 , which is better than the single stock, which met the expectations of the experiment, so the result is meaningful. It is crucial for medium- and long-term investors to account for return predictability, inducing horizon effects in periodic return volatility and correlations [8].

\subsection{Comparison of Individual Assets and Portfolios}

This part will integrate all the previous data to compare the differences between a single stock and a portfolio of stocks. After we construct the portfolio, the standard deviation is significantly reduced. This means 
little data volatility and low-risk factors. In Table 2, the standard deviation of Tencent and Vanke are 0.0832 and 0.0860 , respectively. The standard deviation of the portfolio is 0.0755 . We have minimized the risk and reaped the maximum return on that risk. According to table 5, the research also discovers the weight of the two single stocks in the portfolio.

\subsection{Effects and Results of Research}

I will demonstrate the effects and results of this research. In this research, I built a portfolio of two single stocks. The result met my expectations. I succeeded in maximizing the benefits while minimizing the risks. This also illustrates the importance of building a portfolio. Risk prevention through portfolios can weather short-term market declines and can reduce risk or volatility. But we need to focus that, in the portfolio, if the same type of investment portfolio is invalid, too many products of the same kind, will make your portfolio unbalanced, unknowingly magnified the market risk, hinder the realization of investment objectives $[9,10]$.

\section{CONCLUSION}

In this research, we want to figure out what is essential to build a portfolio and what performance measure can we use to Determine portfolio performance. We select the stock return from the stock market and search the company's return from the annual report. We construct a Global Minimum Variance Portfolio by using the efficient frontier, and we also use the Sharpe ratio to measure the performance between the portfolio and single stock.

To address the above questions, we select two assets from different industries and conduct research. We used the return of stock to finish the independence test and scatterplot. We also used the mean and standard deviation to draw the efficient frontier and found the exact portfolio we wanted.

According to our research, we consider that it is important to construct a portfolio, this can effectively reduce risk, at the same time, and the portfolio I mentioned above is a specific portfolio. Only under the Global Minimum variance Portfolio circumstance can explain that the role of the portfolio is greater than a single stock. We also realize that the Sharpe ratio is also a good way to measure the performance of the asset.

After the research, it reminds the investor that it is unwise to invest in the single stock blindly. Investors should know the background of the enterprise in advance and then choose different industries to build the stock portfolio. Investors shouldn't randomly invest in companies with high returns because high return means high risk. Most of the investors are risk-averse and don't want to afford too much risk.

There were also some flaws in the research. First of all, I chose only two assets, which means that my sample data is small, the results are small, and the argument for the conclusion is not very strong. Second, I only use the Sharpe ratio to compare the portfolio with stock, so I should use more Performance measures to support my opinion in the next research.

\section{REFERENCES}

[1] Lu, Z., From e-heroin to e-sports: The development of competitive gaming in china, The International Journal of The History of The Sport, 2016, vol. 33, pp. 2186-2206. DOI: https://doi.org/10.1080/09523367.2017.1358167

[2] Ma, C.W., Au, N., Social media and learning enhancement among Chinese hospitality and tourism students: A case study on the utilization of Tencent QQ, Teaching in Travel \& Tourism, 2014, vol. 14, pp. 217-239. DOI: https://doi.org/10.1080/15313220.2014.932483

[3] China Internet Network Information Center, the 30th statistical report on internet development in China, 2012. (in Chinese). http://www.cnnic.cn/hlwfzyj/hlwxzbg/hlwtjbg/201 207/t20120723_32497.htm

[4] Kim, J.Y., Windows of opportunity, capability and catch-up: The Chinese game industry, Journal of Contemporary Asia, 2019, vol. 51, pp. 132-156. DOI: https://doi.org/10.1080/00472336.2019.1656761

[5] Zhang, H., Gao, S., J. Seiler, M., Positioning of China's real estate industry based on input-output analysis, Journal of Real Estate Portfolio Management, 2017, vol. 23, pp. 21-33. DOI: https://doi.org/10.1080/10835547.2017.12089995

[6] Szylar, C., Diversification, portfolios of risky assets, and the efficient frontier, Handbook of Market Risk, 2013, chapter. 4, Canada. DOI: https://doi-org/10.1002/9781118572979.ch4

[7] Agarwal, A., Lorig, M., The implied Sharpe ratio, Quantitative Finance, 2020, vol. 20, pp. 1009-1026. DOI:

https://doi.org/10.1080/14697688.2020.1718194

[8] Rehring, C., Real estate in a mixed-asset portfolio: The role of the investment horizon, Real Estate Economics, 2011, vol. 20, pp. 65-95. DOI: https://doi.org/10.1111/j.1540-6229.2011.00306.x

[9] Vaihekoski, M., Portfolio construction for tests of asset pricing models, Financial Market 
Institutions \& Instruments, 2004, pp. 1-39. DOI: https://doi-org/10.1111/j.0963-8008.2004.0001.x

[10] Liu, V., Francis, T., Stock return volatility and the internet phenomenon. Applied Financial Economics Letters, 2006, vol. 2, pp. 105-109. DOI: https://doi.org/10.1080/17446540500447603 